\title{
Tratamento de água com semente de Moringa oleifera
}

\author{
Catharine Borgo ${ }^{1}$; Guilherme Scardua Dellacqua1; Helena Silva Losada Diaz'; \\ Henrique Ferreira Graça Cardoso ${ }^{1}$; Lara Trigo Araújo Mottaํㅜ Yasmin Maria Bispo . \\ 1 Graduação em Engenharia Química, Universidade Federal do Espírito Santo, Alegre, ES, Brasil.
}

* e-mail: henriquecardoso6@hotmail.com

\begin{abstract}
Resumo
É cada vez mais necessário o desenvolvimento de novas formas de tratamento e reutilização de água devido à crise hídrica vivida e à falta de acesso à água de qualidade para boa parte da população. Neste trabalho, foi utilizado um tratamento simples e de fácil aplicação usando sementes de Moringa oleifera. Essa semente possui agentes coagulantes ajudando na remoção da turbidez, da cor e coliformes presentes na água. Esse método em conjunto com a radiação solar, busca uma água potável livre de microrganismos patogênicos e, por ser de fácil aplicação, ajudar na melhoria da qualidade de vida de populações que não tem acesso a água de boa qualidade. Verificou-se uma grande redução na cor e turbidez ao final do tratamento, porém ainda não se pode afirmar que a água é própria para consumo humano pois é necessária uma análise mais criteriosa.
\end{abstract}

\begin{abstract}
It is becoming increasingly necessary the development of new way of water treatment and reuse due to the current water crisis and lack of access to quality water for part of the population. In this study, a simple and easily applicable treatment was used, using Moringa oleifera seeds. This seed has coagulant agents assisting in the removal of turbidity, color, and coliforms present in the water. This method, in combination with the solar radiation, seeks for a potable water free of pathogenic microorganisms and, being easy to apply, helps in the improvement of the quality of life of populations that do not have access to quality water. It was observed a large decrease in color and turbidity at the end of the treatment; however, one cannot state that the water is fit for human consumption, since a more detailed analysis is required.
\end{abstract}

Keywords (Palavras chaves): tratamento de água, Moringa oleífera, Rio Doce.

\section{Introdução}

A água considerada fonte da vida é, para muitas pessoas, escassa ou de baixa qualidade o que provoca a disseminação de doenças por conta da falta de tratamento ideal. Tal problemática pode ser amenizada com o uso da semente de Moringa oleifera, a qual suporta estiagem, solos pobres e cresce mesmo em condições semi-áridas [1].
A população que vive distante dos centros urbanos são as mais prejudicadas pela ingestão de água contaminada, uma vez que não possuem o tratamento nas residências. Sendo assim, a semente da moringa é uma solução acessível para essas pessoas por se tratar de uma planta de fácil cultivo e baixo custo.

As sementes têm sido empregadas no tratamento de águas brutas e efluentes, tendo como principais 
resultados a remoção da cor e turbidez, além de microorganismos. Elas agem pelo processo de coagulação da matéria em suspensão, seguida pela floculação e sedimentação [2].

O objetivo do tratamento da água com a semente triturada é a possibilidade de ser realizada em diversos locais, a baixo custo e sem o uso de energia elétrica. Apesar de simples, o procedimento é capaz de eliminar até $90 \%$ da turbidez e das bactérias presentes no meio [3].

\section{Materiais e Métodos}

- Sementes de Moringa Oleífera;

- 1,5 L de água coletada do Rio Doce em Colatina;

- 3 garrafas pets de $500 \mathrm{ml}$;

- 2 garrafas pets de $2 \mathrm{~L}$;

- Peneira;

- Faca;

- Pote plástico e socador;

- Caixa de sapato;

- Papel alumínio;

- Papel filme;

- Durex;

- Turbidímetro.

O presente trabalho foi realizado no campus de Alegre da Universidade Federal do Espirito Santo (UFES).

Foram descascadas 3 sementes de Moringa oleifera e trituradas no pote com o auxílio de um socador. Após trituradas, as sementes foram misturadas junto a aproximadamente 1,3 $\mathrm{L}$ de água coletada do rio doce. Guardou-se o restante da água para análise das propriedades desta.

A água com as sementes foi agitada intensamente e dividida em 3 amostras, armazenadas em garrafas pets de $2 \mathrm{~L}$ cortadas ao meio. Posteriormente, os recipientes foram deixados em repouso para uma completa sedimentação. A primeira amostra foi recolhida após 8 horas em repouso, a segunda após 12 horas e a terceira após 24 horas.

Assim que retiradas do descanso cada amostra foi filtrada com a ajuda de uma peneira e transferida para garrafas pet de $500 \mathrm{ml}$. Estas garrafas foram colocadas dentro de uma caixa de sapato revestida com papel alumínio e coberta por papel filme. A caixa foi exposta a radiação solar por cerca de 12 horas.

Logo após esse período a água foi recolhida para ser realizada a análise em laboratório, assim como a água antes do tratamento. As amostras foram analisadas no turbidímetro do laboratório de química.

\section{Resultados e Discussão}

A Moringa oleifera atua como um coagulante natural. A coagulação forma flocos com densidade superior à da água, os quais ficarão depositados no fundo da garrafa. Essa age como um decantandor, onde separa sólidos em suspenção na água a ser tratada.

Turbidez é um parâmetro no controle da qualidade da água, a qual mede a quantidade de partículas em suspenção no líquido e esse valor é expresso em Unidade Nefelométrica de Turbidez (UNT).

Com o auxílio do turbidímetro, é possível perceber a diminuição no valor de UNT das amostras com o passar do tempo, entretanto não foi possível uma análise da concentração de metais no fluido devido à falta de equipamentos.

Os valores de turbidez encontrados para as amostras de água tratada podem ser visualizados na Tabela 1 :

Tabela 1: Valores de turbidez para as amostras de água.

\begin{tabular}{|c|c|c|c|c|}
\hline Amostra & Coletada & $\begin{array}{c}8 \text { horas de } \\
\text { tratamento }\end{array}$ & $\begin{array}{c}12 \text { horas } \\
\text { de } \\
\text { tratamento }\end{array}$ & $\begin{array}{c}24 \text { horas } \\
\text { de } \\
\text { tratamento }\end{array}$ \\
\hline Turbidez & 275 UNT & 140 UNT & 116 UNT & 44 UNT \\
\hline
\end{tabular}

A partir dos valores encontrados, é possível notar que a semente de Moringa oleifera apresenta bons resultados no processo de coagulação dos sólidos, sendo observado que o tratamento realizado com 24 horas, constatou-se uma purificação acentuada da água em relação aos demais. O menor valor de turbidez obtido foi de 44 UNT, entretanto o valor máximo permitido para considerar a água como potável é de 5 UNT. Para a realização do experimento utilizou-se 1 semente para 
aproximadamente $500 \mathrm{ml}$ de água, o que fortalece a ideia de baixo custo no tratamento, visto que a planta pode ser cultivada em diversas regiões [4].

A diferença entre a turbidez das amostras pode ser observada na Figura 1, onde também é notável a diferença de cor entre a amostra coletada do Rio Doce e as amostras de 8,12 e 24 horas de tratamento, respectivamente.

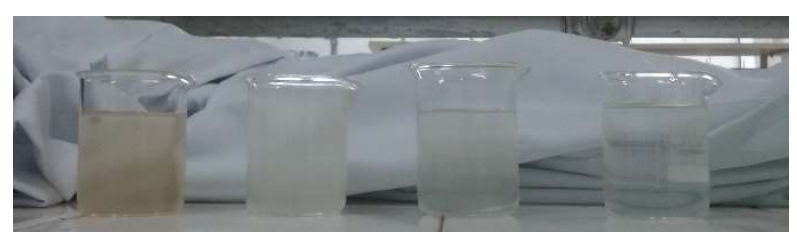

Figura 1: Amostras de água. Da esquerda para a direita: amostra do Rio Doce, amostras de 8, 12 e 24 horas após o tratamento.

No entanto, a análise na qual verifica-se a quantidade de coliformes fecais e totais não foi possível ser realizada devido à ausência de equipamentos, mas de acordo com a literatura é possível inferir que a utilização dos raios UV com o forno solar e a própria semente promove uma eliminação de microorganismos contidos na água [5].

\section{Conclusão}

O presente trabalho apresentou uma boa queda no valor de turbidez da água com o tempo de 24 horas. Este tempo ainda não foi o suficiente para se obter uma água completamente própria para o consumo humano, no entanto, mostrou-se que a semente de Moringa oleifera, caso seja mais estudada, pode ser aplicada para o tratamento de água para comunidades ribeiras e com difícil acesso à água tratada.
Com a atual situação do Rio Doce é de grande importância que novas técnicas de tratamento de água sejam aprimoradas, visto que pequenas vilas não possuem grandes investimentos e esse método possui baixo custo e pode ser realizado pelo próprio consumidor.

\section{Referências}

[1] MONACO, P. A. V. L. et al. Utilização de extrato de sementes de moringa como agente coagulante no tratamento de água para abastecimento e águas residuárias. Ambi-Água, Taubaté, v. 5, n.3, p. 222-231, 2010.

[2] SILVA, F. J. A.; MATOS, J. E. X. Sobre dispersões de Moringa oleifera para tratamento de água. Rev. Tecnol. Fortaleza, v. 29, n. 2, p. 157-163, dez. 2008. Universidade de Fortaleza, CE.

[3] CARDOSO, K. C. et al. Otimização dos tempos de mistura e decantação no processo de coagulação/floculação da água bruta por meio da Moringa Oleifera Lam. Acta Sci. Tech., v. 30, n. 2, p. 193-198, 2008, Maringá.

[4] SABESP. Disponível em:

$<$ http://site.sabesp.com.br/site/interna/Default.aspx?sec aold=40>. Acesso em 4 de novembro de 2016.

[5] JUNIOR, W. C. S., et al. Tratamento de água contaminada com Moringa Oleifera. 2010, Instituto Federal Fluminense, RJ. 